PAPER

\title{
Incidence of endemic ataxic polyneuropathy and its relation to exposure to cyanide in a Nigerian community
}

\author{
O S A Oluwole, A O Onabolu, I A Cotgreave, H Rosling, A Persson, H Link
}

J Neurol Neurosurg Psychiatry 2003;74:1417-1422

See end of article for authors' affiliations

Correspondence to:

Dr Oluwole, Department of Neuroscience, SE-171 77, Stockholm, Sweden osaoluwole@hotmail.com

Received 12 January 2003 In revised form 12 March 2003

Accepted 14 March 2003
Background: The occurrence of ataxic polyneuropathy in an endemic area in south west Nigeria has been attributed to exposure to cyanide from cassava foods. However, it has been shown that the prevalence of ataxic polyneuropathy is not high in several communities in the tropics where exposure to cyanide from cassava foods is high.

Objectives: To determine the incidence of ataxic polyneuropathy in an endemic community, and to compare the intake of cassava foods, exposure to cyanide, and levels of thiols in cases and controls. Methods: A cohort of 3167 healthy subjects aged 10 years and over in Ososa, Nigeria, was followed for two years, screened, and examined neurologically. Ataxic polyneuropathy was diagnosed if sensory polyneuropathy and sensory gait ataxia were both present. Controls were selected randomly within 10 year age groups of subjects who screened negative. Intake of cassava foods, exposure to cyanide, concentrations of thiols (glutathione, cysteine, and $\gamma$ glutamylcysteine) in plasma, and visual evoked potentials were measured.

Results: Person-years of follow up were 6246 for 1469 male and 1698 female subjects in the cohort. The incidence of ataxic polyneuropathy was 64 per 10000 person-years (31 for male and 93 for female subjects). Multivariate odd ratios were 0.78 (95\% $\mathrm{Cl} 0.23$ to 2.61$)$ for intake of the commonest cassava food, and 1.64 (0.56 to 5.09) for concentration of thiocyanate in plasma. The concentration of thiols was less than the reference limits in two controls, but in none of the cases. The latency of P100 was prolonged in 20 cases $(69 \%)$ compared with 14 controls $(42 \%)(p<0.05)$.

Conclusions: The incidence of ataxic polyneuropathy is high in Ososa, Nigeria, but the intake of cassava foods, exposure to cyanide, and levels of thiols, are not related to the occurrence. These findings do not suggest that cyanide is the cause of endemic ataxic polyneuropathy.
A taxic polyneuropathy occurs in different regions of the world in sporadic, ${ }^{1}$ epidemic, ${ }^{2}$ and endemic forms. ${ }^{1}$ However, endemic ataxic polyneuropathy has been reported predominantly from some communities in south western Nigeria. ${ }^{13}$ The prevalence of ataxic polyneuropathy in the endemic area ranged from $2.2 \%$ to $7 \%$ in the 1950 s and 1960s. ${ }^{134}$ Although it was thought that this condition had ceased to occur about two decades ago, ${ }^{5}$ a recent study ${ }^{6}$ showed a prevalence of $6 \%$ in a community in the endemic area.

The aetiology of endemic ataxic polyneuropathy is not known, ${ }^{2}$ but deficiencies of micronutrients or exposure to toxic agents have been suggested. ${ }^{78}$ Epidemiological studies conducted in the 1950s and 1960s in Nigeria showed higher intakes of cassava foods in communities in the endemic area than in non-endemic areas. ${ }^{49}$ Although recent studies have confirmed a high intake of cassava foods in some endemic communities, ${ }^{10}{ }^{11}$ high intakes have also been reported in non-endemic communities. ${ }^{11}$

The relation between the occurrence of endemic ataxic polyneuropathy and exposure to cyanide from cassava foods remains unclear almost 50 years after the hypothesis was first proposed. ${ }^{13^{4}}$ The findings of a study ${ }^{12}$ showing a low prevalence of ataxic polyneuropathy in a community where exposure to cyanide from cassava foods was high suggest that exposure to cyanide from these foods may not be the cause of the disease. Although several studies have shown that cassava food intake is high in the endemic area for ataxic polyneuropathy in Nigeria, ${ }^{14}$ intakes of these foods and exposure to cyanide have not been compared in cases and controls living in the same community.
Our aim in this study was to determine the incidence of ataxic polyneuropathy in an endemic community in Nigeria, and to compare the intake of cassava foods, exposure to cyanide from cassava foods, and plasma concentrations of thiols (which are required to detoxify cyanide) in incident cases and controls.

\section{METHODS}

\section{Study site}

The study was conducted in Ososa, a community in south western Nigeria, which is located on latitude $6.71 \mathrm{~N}$ and longitude $3.53 \mathrm{E}$. This semiurban community is within the area that was defined as endemic for ataxic polyneuropathy ${ }^{134}$ (fig 1). A de facto census that was done in $1998^{6}$ showed that about 5000 people reside in the community. The prevalence of ataxic polyneuropathy was determined in Ososa in $1969^{\circ}$ and $1998 .^{6}$

\section{Definition of a case of ataxic polyneuropathy}

In the 1960s ataxic polyneuropathy was defined as the presence of any two of the following features: sensory polyneuropathy, sensory gait ataxia, optic atrophy, and neurosensory deafness. ${ }^{9} 13$ During a prevalence study in Ososa in $1998,{ }^{8}$ we observed, however, that several combinations of signs without sensory gait ataxia and sensory polyneuropathy would be diagnosed as ataxic polyneuropathy when the case definition of the 1960s was used. To

Abbreviations: VEP, visual evoked potential 


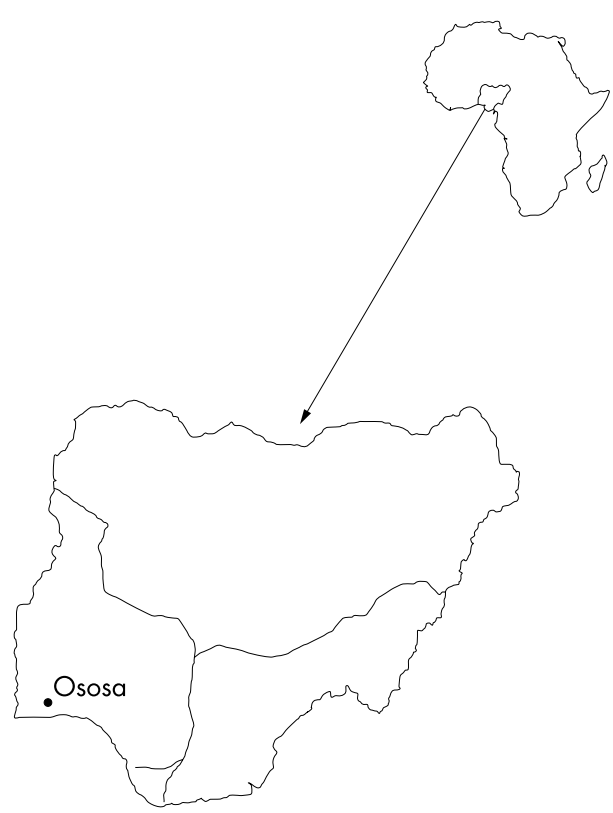

Figure 1 Map of Nigeria showing the location of the study community.

prevent such misdiagnoses the definition of was made more stringent in this study by the requirement for the presence of both symmetrical sensory polyneuropathy and sensory gait ataxia in every case.

\section{Establishment of the cohort and screening}

In a previous study ${ }^{6}$ all subjects aged 10 years and above in Ososa were screened and examined for ataxic polyneuropathy, using the case definition of the 1960s. All subjects living in Ososa who were not diagnosed as having ataxic polyneuropathy or other neurological illness formed a cohort that was followed for two years in the present incidence study. All deaths and movements out of the cohort were recorded.

At the end of the follow up, the cohort was screened with a tandem-walk test, which was standardised from descriptions in textbooks. ${ }^{14}{ }^{15}$ To undertake the tandem-walk test subjects were instructed to stand with both feet together, look straight ahead and not at the ground, and walk heel to toe in a straight line over a distance of three metres without hesitation or stopping, with both hands by the sides and not swinging. ${ }^{12}$ Inability to tandem-walk, or stepping out of a straight line consistently after three trials, was considered a positive test. Subjects who were positive on the tandem-walk test were invited for a neurological examination. The sensitivity of the tandem-walk test as a screening test for ataxic polyneuropathy was previously shown to be $100 \%$, with a specificity of $58 \%{ }^{16}$

A full medical history and a history of exposure to pesticides, industrial chemicals, drugs, smoking, and alcohol were obtained from each subject. A neurological examination was done as described in standard texts. ${ }^{14}{ }^{15}$

\section{Cases and controls}

Cases of ataxic polyneuropathy and subjects who screened negative on the tandem-walk test were grouped into 10 year age categories of each sex. Three controls were selected randomly for each case within the 10 year age categories of subjects who screened negative.

\section{Blood and urine samples}

Samples of venous blood, which were collected after an overnight fast, were centrifuged immediately, and the plasma kept on ice during transportation to the laboratory, where they were stored at $-80^{\circ} \mathrm{C}$ until analysis. Four hour timed urine samples were collected between about $8.00 \mathrm{am}$ and 12.00 noon. Subjects were given a jar in which to collect their urine after emptying their bladder under supervision. Final urine samples, which were collected at the end of four hours under supervision, were tested for sugar and protein. The volumes of urine were measured and aliquots were stored at $-80^{\circ} \mathrm{C}$ until analysis.

The concentrations of thiocyanate in plasma and urine were determined using previously described methods. ${ }^{17}$ The concentrations of cysteine, glutathione, and $\gamma$-glutamylcysteine, the major low molecular weight thiols in the plasma, were determined using established methods. ${ }^{18}$ Briefly, low molecular weight thiols in the plasma were reduced with dithiothreitol and derivatised with monobromobimane. ${ }^{18}$ Protein was precipitated from samples with trichloroacetic acid. Samples were centrifuged, and $25 \mu \mathrm{l}$ of the supernatant was applied to an HPLC column to determine the thiol-bimane adducts. ${ }^{18}$

The concentrations of creatinine ${ }^{19}$ and of inorganic sulphate ${ }^{20}$ were determined using standard methods. The excretion of creatinine and thiocyanate in the urine per hour was calculated. The reference limits for thiocyanate, thiols, and inorganic sulphate were as previously published. ${ }^{12}$

\section{Food history and body mass index}

A history of all foods eaten during the week preceding the day the urine and blood samples were collected was obtained from the subjects. The number of meals and quantities of gari, lafun, and fufu, the local foods that are processed from cassava roots, were counted from the diet history of each subject. As eba, another cassava food, is prepared by adding boiling water to gari, it was counted separately from the diet history. An intake of cassava foods of five or more times a week was considered high, based on the local consumption pattern, previous reports, ${ }^{1}$ and estimates of levels of cyanogenic compounds in gari sold in Nigeria. ${ }^{11}$

Semiquantitative methods were used to estimate the amounts of protein in the foods. ${ }^{21}$ The amount of protein taken per day was calculated for each subject. The reference lower limit for intake of protein was $0.75 \mathrm{~g} / \mathrm{kg}$ body mass per day. ${ }^{22}$ Body mass $(\mathrm{kg})$ and height $(\mathrm{m})$ were measured for each subject, and the body mass index (BMI) was calculated using the formula body mass/height ${ }^{2}$. The reference lower limit for the BMI was 18.5. ${ }^{23}$

\section{Neurophysiological tests}

Visual evoked potential (VEP) responses were examined using portable neurophysiology equipment (Medilec Synergy). The scalps of subjects were cleansed with abrasive cream or acetone until the resistance was less than $4000 \Omega{ }^{24}$ The recording scalp electrode, which was placed $5 \mathrm{~cm}$ above the inion, ${ }^{25}$ was referenced to Fpz, and the ground electrode was placed at Cz. The stimulator, which was a 15 inch liquid crystal display personal computer monitor, was placed $1 \mathrm{~m}$ in front of the subject's face in the sitting position. The pattern stimulator operated at two reversals a second. Subjects were instructed to gaze at a spot at the centre of checkers of size 16. Each eye was recorded separately in full field.

Three trials, each of 100 sweeps, were recorded for each subject. ${ }^{26}$ Latency was measured from departures from baseline, and amplitude from baseline to peak. ${ }^{24}$ Prolonged latency in one eye was considered abnormal. Visual acuity was tested at the bedside. Subjects with impairment of vision or cataracts were excluded. All recordings were done in a darkened room in the local primary health care clinic in the community. Nerve conduction tests were attempted, but not successful because of technical problems with the electrical 
Table 1 Distribution of subjects in the cohort and subjects censored

\begin{tabular}{|c|c|c|c|c|c|c|c|c|}
\hline \multirow[b]{2}{*}{ Age group (years) } & \multicolumn{2}{|c|}{ Cohort } & \multicolumn{2}{|c|}{ Moved* } & \multicolumn{2}{|l|}{ Died } & \multicolumn{2}{|c|}{ Screened $\dagger$} \\
\hline & Male & Female & Male & Female & Male & Female & Male & Female \\
\hline 10 to 19 & 563 & 504 & 9 & 7 & 1 & 2 & 533 & 495 \\
\hline 20 to 29 & 220 & 350 & 3 & 11 & 0 & 1 & 203 & 338 \\
\hline 30 to 39 & 184 & 259 & 3 & 4 & 2 & 0 & 167 & 255 \\
\hline 40 to 49 & 155 & 175 & 1 & 4 & 7 & 2 & 143 & 169 \\
\hline 50 to 59 & 126 & 150 & 2 & 4 & 3 & 1 & 119 & 145 \\
\hline 60 to 69 & 124 & 119 & 3 & 1 & 6 & 2 & 115 & 116 \\
\hline 70 to 79 & 62 & 74 & 1 & 0 & 5 & 9 & 56 & 65 \\
\hline 80 to 89 & 27 & 58 & 0 & 1 & 3 & 8 & 24 & 49 \\
\hline 90 to 99 & 7 & 7 & 0 & 0 & 2 & 1 & 5 & 6 \\
\hline$\geqslant 100$ & 1 & 2 & 0 & 0 & 1 & 1 & 0 & 1 \\
\hline Total & 1469 & 1698 & 22 & 32 & 30 & 27 & 1365 & 1639 \\
\hline
\end{tabular}

*Subjects who moved out of the community during the follow up period.

†Subjects who were screened for ataxic polyneuropathy at the end of the follow up period.

setup in the room used for neurophysiology in the community.

The subjects used for determination of reference values for VEP were selected from another Nigerian community, which is located in the non-endemic area in Nigeria where exposure to cyanide from cassava food is high, but where the prevalence of ataxic polyneuropathy is low. ${ }^{12}$ The controls were randomly selected from among persons aged 60 to 80 years in the community. The $95 \%$ interpercentile range for the P100 latency was 108 to $125 \mathrm{~ms}(\mathrm{n}=26)$, while the $95 \%$ interpercentile range for the P100 amplitude was 5 to $21 \mu \mathrm{V}$.

\section{Statistical analysis}

Subjects who died or moved out of the community during the follow up period were censored. Total follow up period was calculated by summing up the duration of follow up for each subject. The incidence rate was calculated per 10000 personyears. Risk factors were compared between cases and controls using univariate analysis and a multiple logistic regression model. Univariate and multivariate odds ratios of the risk factors were calculated. P100 latency and amplitude of the visual evoked potentials for cases and controls were compared using the $\chi^{2}$ test. Statistical calculations were done using SPSS version 10.1, EPI info version 6, and Medcalc.

\section{RESULTS}

\section{Incidence}

There were 3167 subjects in the cohort, 1469 male and 1698 female. The distribution of age and sex of the subjects is shown in table 1 . We censored 111 subjects - 54 who moved out of the community and 57 who died. The mean (SD) age of subjects who moved out of the community during the follow up was 33 (18) years (median 28, range 10 to 80 ), and of those who died, 65 (21) years (median 70, range 10 to 105). Of 3056 subjects who were alive at the end of follow up, 52 were not available at the time of screening, and of the 3004 subjects who were screened, 271 who screened positive for ataxic polyneuropathy were invited for neurological examination. Twelve of these defaulted from the neurological examination. After the examination, ataxic polyneuropathy was diagnosed in 40 subjects ( 31 female and nine male). Seven of these had neurosensory deafness, but none had optic atrophy. None of the subjects had clinical or laboratory evidence of alcoholism, diabetes mellitus, or chronic renal failure, and none had been exposed to pesticides. No clinical features of malnutrition or vitamin deficiency were observed in any subject.

Person-years of follow up, distribution of the ages of subjects with ataxic polyneuropathy, and age and sex specific incidence rates are shown in table 2 . Total person-years of follow up were 6246.2. The incidence of ataxic polyneuropathy was 64 per 10000 person-years in people aged 10 years or more in Ososa (31 per 10000 for male subjects and 93 per 10000 for female subjects). The age specific incidence rate was highest in the 70 to 79 year age group for both sexes. The approximate cumulative incidence was 63 per 10000 per year (31 per 10000 per year for male subjects, and 91 per 10000 per year for female subjects).

\section{Nested case-control}

All subjects who were selected for the case-control study agreed to participate, but only those who gave consent to venesection (23 $58 \%$ ) of 40 cases of ataxic polyneuropathy and $60(50 \%)$ of 120 controls) were included in the casecontrol study. Although the response rate was about $50 \%$, there was no evidence that those who refused venesection were different from those who accepted with respect to their

Table 2 Distribution of person-years of follow up and age specific incidence rates

\begin{tabular}{|c|c|c|c|c|c|c|}
\hline \multirow{2}{*}{$\begin{array}{l}\text { Age group } \\
\text { (years) }\end{array}$} & \multicolumn{2}{|c|}{$\begin{array}{l}\text { Person-years of } \\
\text { follow up }\end{array}$} & \multicolumn{2}{|l|}{ Cases } & \multicolumn{2}{|c|}{$\begin{array}{l}\text { Age specific incidence (per } 10000 \\
\text { person-years) }\end{array}$} \\
\hline & Male & Female & Male & Female & Male & Female \\
\hline 10 to 19 & 1116.9 & 1006.0 & 0 & 0 & 0 & 0 \\
\hline 20 to 29 & 438.8 & 691.3 & 0 & 0 & 0 & 0 \\
\hline 30 to 39 & 364.7 & 514.9 & 0 & 0 & 0 & 0 \\
\hline 40 to 49 & 304.3 & 344.5 & 0 & 3 & 0 & 87 \\
\hline 50 to 59 & 249.2 & 293.3 & 0 & 5 & 0 & 170 \\
\hline 60 to 69 & 240.0 & 237.0 & 3 & 9 & 125 & 380 \\
\hline 70 to 79 & 117.9 & 139.9 & 4 & 11 & 339 & 786 \\
\hline$\geqslant 80$ & 63.3 & 124.1 & 2 & 3 & 315 & 241 \\
\hline Total & 2895.1 & 3351.1 & 9 & 31 & 31 & 93 \\
\hline
\end{tabular}


Table 3 Risk factors and odds ratios

\begin{tabular}{|c|c|c|c|c|}
\hline & \multicolumn{4}{|c|}{ Odds ratios } \\
\hline & \multicolumn{2}{|c|}{ Univariate $(\mathrm{CI})$} & \multicolumn{2}{|c|}{ Multivariate (CI) } \\
\hline & 0.36 & (0.11 to 1.21$)$ & 0.33 & (0.09 to 1.18$)$ \\
\hline Age ( 40 to 60 years, $>60$ years $)$ & 2.56 & (0.77 to 8.52$)$ & 3.79 & $(0.96$ to 14.96$)$ \\
\hline $\mathrm{BMI}\left(\geqslant 18.5,<18.5 \mathrm{~kg} / \mathrm{m}^{2}\right)$ & 1.39 & (0.42 to 4.62$)$ & 1.12 & $(0.33$ to 3.85$)$ \\
\hline Gari* & 0.76 & $(0.24$ to 2.40$)$ & 0.76 & $(0.21$ to 2.78$)$ \\
\hline$E b a^{*}$ & 0.87 & (0.31 to 2.40$)$ & 0.78 & $(0.23$ to 2.61$)$ \\
\hline Plasma thiocyanate $(0-6 \mu \mathrm{mol} / \mathrm{l},>66 \mu \mathrm{mol} / \mathrm{l})$ & 1.64 & $(0.62$ to 4.30$)$ & 1.69 & (0.56 to 5.09 ) \\
\hline
\end{tabular}

intake of cassava foods or exposure to cyanide. There were 26 male and 57 female subjects in the nested case-control study. The mean (SD) age of the cases was 69 (10) years (range 45 to 84 ), and the mean age of the controls was 65 (11) years (range 40 to 89 ).

The distribution of risk factors and their odds ratios are shown in table 3. The BMI values of six cases and 14 controls were below the reference limits $(p>0.05)$. Five cases $(22 \%)$ compared with 16 controls (27\%) took gari above the reference limit, while 15 cases $(65 \%)$ compared with 41 controls $(68 \%)$ took $e b a$ above the reference limit. There was no statistical difference in the intake of all cassava foods between cases and controls, and between male and female subjects $(\mathrm{p}>0.05)$. Twelve cases $(52 \%)$ compared with 24 controls $(40 \%)$ had levels of thiocyanate above the reference limits. Exposure to cyanide was not significantly different between cases and controls $(\mathrm{p}>0.05)$.

The concentrations of cysteine and $\gamma$-glutamylcysteine in the plasma were less than the reference limits in two controls and in none of the cases, while plasma glutathione was below the reference limit in four controls and in one case. The total thiol level was below the reference limit in two controls and in none of the cases; therefore thiols were not included in the multivariate model. The univariate odds ratio was 2.67 (95\% confidence interval, 0.89 to 7.96 ) for the excretion of inorganic sulphate. The P100 latency was prolonged in 20 of 29 cases compared with 14 of 33 controls $(p<0.05)$. The P100 amplitude was reduced in 11 of 29 cases compared with 15 of 33 controls $(\mathrm{p}>0.05)$.

\section{DISCUSSION}

Our study shows that new cases of ataxic polyneuropathy still occur in Ososa, a community in the endemic area for ataxic polyneuropathy in south west Nigeria. In 1969 the prevalence of ataxic polyneuropathy was 22 per 1000 in Ososa, ${ }^{9}$ while in 1998 a study $^{6}$ using the same case definition of the 1960s found a prevalence of 60 per 1000 in the same area. The incidence of 64 per 10000 person-years in this study suggests that the occurrence of ataxic polyneuropathy in Ososa, and probably in other communities in the endemic area, remains high, although several communities which were studied in the $1950 \mathrm{~s}^{327}$ and $1960 \mathrm{~s}^{14}$ have not been restudied. The absence of previous data on incidence, ${ }^{7}$ however, precludes firm conclusions about changes in the rate of occurrence.

Ataxic polyneuropathy has been described predominantly in the elderly population in prevalence studies. ${ }^{16}$ The fact that the highest age specific incidence rate was in the 60 to 79 year age range in our study provides further support for this being predominantly a disease of the elderly. It has been suggested that it may be a neurodegenerative disease, ${ }^{9}$ although exposure to toxins and deficiencies of micronutrients have been the focus of most studies.
The male to female incidence rate ratio of $1: 3$ in this study shows that the disease is more common in women. The predominance of women has also been reported in prevalence studies. ${ }^{46}$ The reason for a higher prevalence in women is not known, but it is unlikely to reflect a greater exposure to cyanide from cassava foods. In this study there was no difference in the intake of cassava foods or exposure to cyanide between male and female subjects, although the number of male cases was small. A study of 21 communities in Nigeria ${ }^{16}$ also showed similar intakes of cassava foods and similar exposure to cyanide in male and female subjects.

The cause of endemic ataxic polyneuropathy has been attributed to exposure to cyanide from cassava foods. ${ }^{47}$ This hypothesis is based largely on studies which showed high intakes of cassava foods and high levels of thiocyanate in plasma and urine of subjects in the endemic area in Nigeria. ${ }^{1328}$ However, the level of intake of cassava foods in cases of endemic ataxic polyneuropathy and their family members was similar in another study. ${ }^{13}$ In the present study the level of intake of cassava foods was also similar in cases and controls. Studies of the intake of cassava foods in Nigeria have shown that variations in intake within specific ethnic groups are small, while variations in intake between ethnic groups are large. ${ }^{11} 16$

Cassava roots, from which several foods are processed, ${ }^{29}{ }^{30}$ contain cyanogenic compounds that are usually reduced during processing. ${ }^{10}$ Cyanogenic compounds, however, often remain in cassava foods because the methods of processing cassava roots are not $100 \%$ efficient. ${ }^{10}{ }^{12}$ Although hydrogen cyanide is rarely detected in these foods, ${ }^{12}{ }^{31}$ consumption of foods containing cyanogenic compounds has been shown to result in exposure to cyanide, though the amount of cyanide absorbed from a single meal is small. ${ }^{16}{ }^{32}$

Cyanide is metabolised to several compounds such as thiocyanate, cyanate, formate, and 2-iminothiazolidine-4carboxylic acid, ${ }^{33}$ but the major metabolite is thiocyanate. ${ }^{33}$ Thiols, which are sources of sulphur, are required to detoxify cyanide to thiocyanate. ${ }^{34}$ It has been hypothesised that the detoxification of cyanide to thiocyanate may be impaired in cases of ataxic polyneuropathy because of a deficiency of thiols. ${ }^{13}$ The metabolism of cyanide to thiocyanate has not, however, been shown to be impaired, even in starvation. ${ }^{35}$ This may reflect the continuous release of amino acids from the lean body mass during starvation. Experimental studies do not show impairment of detoxification of cyanide to thiocyanate in rats on low protein ${ }^{36}$ or a diet containing no sulphur amino acids. ${ }^{37}$

In this study the finding of similar levels of thiols in cases and controls does not suggest deficiency of substrates needed to detoxify cyanide to thiocyanate in ataxic polyneuropathy. Studies that have shown high rather than low levels of thiocyanate in cases of ataxic polyneuropathy ${ }^{13}$ do not support the notion of impairment of detoxification of cyanide to thiocyanate in this disease. Specific deficiencies of 
vitamins and other micronutrients have not been found, except for the presence of low levels of riboflavin in one study. ${ }^{38}$ Assays of $\mathrm{B}$ vitamins ${ }^{7}$ and levels of methylmalonic acid in the urine were normal. ${ }^{39}$ No change in the clinical status of the subjects was observed in clinical trials with protein and vitamin supplements. ${ }^{40} 41$

Although the clinical features of ataxic polyneuropathy seen in Nigeria suggest peripheral and central nervous system pathology, ${ }^{6}{ }^{13} 16$ detailed neuropathological or neuroimaging studies have not been done to define the nature of the lesions clearly. In this study the delayed P100 amplitude of the VEP suggests demyelination of the optic nerves. The neurophysiological investigations in our study were, however, too limited to allow any conclusions to be drawn on possible pathology in the neuroaxis and peripheral nerves.

There are several limitations to a study of the relation between exposure to cyanide from the intake of cassava foods and the occurrence of ataxic polyneuropathy. It is difficult to estimate exposure to cyanide from the frequency of intake of cassava foods because of the wide variation in levels of cyanogenic compounds in foods that are processed using different methods. ${ }^{12}$ Differences in the duration of storage, during which cyanogenic compounds are lost, ${ }^{42}$ also contribute to the difficulty in estimating exposure to cyanide from cassava food intake. In addition, the duration of exposure to cyanide from cassava foods in the endemic community is difficult to measure accurately because the intake of these foods starts in early childhood in such communities. ${ }^{16}$

Thiocyanate levels have been used in several studies to measure exposure to cyanide quantitatively. ${ }^{43}{ }^{44}$ It has been shown that thiocyanate concentrations in the urine correlate with the intake of gari, the most popular cassava food in Nigeria. ${ }^{16}$ However, it is only possible to assess the intake of cassava foods in the short term by thiocyanate levels. Although there are weaknesses in the use of short term food history and of biomarkers of exposure in the short term to assess the usual food intake, ${ }^{45}$ studies conducted in the endemic communities in the past 30 years have shown similar patterns of intake of cassava foods.

Although the focus of research on the cause of endemic ataxic polyneuropathy has been on nutritional and toxic factors, inflammatory factors have also been considered. ${ }^{6}$ Treponemal infections were excluded in the $1950 \mathrm{~s}^{46}$ and 1960s. ${ }^{13}$ Recent studies have shown, however, that HTLV-1 is associated with myelopathies in some tropical communities. ${ }^{47}$ Although the clinical features of HTLV-1-associated myelopathies do not strictly resemble those of endemic ataxic polyneuropathy, ${ }^{6}$ there is a need to exclude retroviral infections in subjects with endemic ataxic polyneuropathy.

\section{Conclusions}

Our findings show that new cases of ataxic polyneuropathy are still occurring in Ososa, Nigeria, but the similarity in the intake of cassava foods and exposure to cyanide in cases and controls does not support the hypothesis that cyanide is the cause of this disease.

\section{ACKNOWLEDGEMENT}

The study was funded by the International Programme in Chemical Sciences, Uppsala University, Sweden.

\section{Authors' affiliations}

O S A Oluwole, Neurology Unit, Department of Medicine, College of Medicine, University of Ibadan, Ibadan, Nigeria

A O Onabolu, H Rosling, Division of International Health, Department of Public Health Sciences, Karolinska Institute, Sweden

I A Cotgreave, Division of Biochemical Toxicology, Institute of Environmental Medicine, Karolinska Institute
A Persson, Department of Clinical Neurophysiology, Huddinge University Hospital, Karolinska Institute

H Link, Department of Neurology, Huddinge University Hospital, Karolinska Institute

Competing interests: none declared

\section{REFERENCES}

1 Osuntokun BO. Epidemiology of tropical nutritional neuropathy in Nigerians. Trans R Soc Trop Med Hyg 1971; 65:454-79.

2 Roman GC, Spencer PS, Schoenberg BS. Tropical myeloneuropathies: the hidden endemias. Neurology 1985;35:1158-70.

3 Money GL. Endemic neuropathies in the Epe district of southern Nigeria. West Afr Med J 1958;7:58-62.

4 Monekosso GL, Annan WGT. Clinical epidemiological observations on an ataxic syndrome in western Nigeria. Trop Geogr Med 1964;4:316-23.

5 Osuntokun BO. Chronic cyanide intoxication of dietary origin and a degenerative neuropathy in Nigerians. Acta Horticulturae 1994;375:271-83.

6 Oluwole OSA, Onabolu AO, Link $\mathrm{H}$, et al. Persistence of tropical ataxic neuropathy in a Nigerian community. I Neurol Neurosurg Psychiatry 2000;69:96-101.

7 Osuntokun BO. Cassava diet, chronic cyanide intoxication and neuropathy in the Nigerian Africans. World Rev Nutr Diet 1981;36:141-73.

8 Roman G. Tropical myeloneuropathies revisited. Curr Opin Neurol 1998;11:539-44.

9 Osuntokun BO, Monekosso GL, Wilson J. Relationship of a degenerative tropical neuropathy to diet report of a field survey. BMJ 1969;i:547-50.

10 Onabolu AO, Bokanga M, Rosling H. Cassava processing in a Nigerian community affected by a neuropathy attributed to dietary cyanide exposure. Trop Sci 1999;39:129-35.

11 Onabolu AO, Oluwole OSA, Bokanga M, et al. Ecological variation of intake of cassava food and dietary cyanide load in Nigerian communities. Public Health Nutr 2001:4:871-6.

12 Oluwole OSA, Onabolu AO, Cotgreave IA, et al. Low prevalence of ataxic polyneuropathy in a community with high exposure to cyanide from cassava foods. J Neurol 2002;249:1034-40.

13 Osuntokun BO. An ataxic neuropathy in Nigeria: a clinical, biochemical and electrophysiological study. Brain 1968;91:215-48.

14 DeMyer W. Technique of the neurologic examination: a programmed text. New York: McGraw-Hill, 1994.

15 Adams R, Victor M, Ropper AH. Principles of neurology. New York: McGrawHill, 1997:1618.

16 Oluwole OSA. Endemic ataxic polyneuropathy in Nigeria. Stockholm: Karolinska Institute Department of Public Health Sciences, 2002:71.

17 Lundquist P, Kagedal B, Nilsson L. An improved method for determination of thiocyanate in plasma and urine. Eur J Clin Chem Clin Biochem 1995;33:343-9.

18 Cotgreave IA, Moldéus P. Methodologies for the application of monobromobimane to the simultaneous analysis of soluble and protein thiol components of biological systems. J Biochem Biophys Methods 1986;13:231-49.

19 Sieldel J, Deeg R, Seidel H, et al. Fully enzymatic colorimetric assay of serum and urine creatinine which obviates the need for sample blank measurements. Anal Lett 1988;21:1009-17.

20 Lundquist P, Mårtensson J, Sörbo B, et al. Turbidimetry of inorganic sulfate, ester sulfate, and total sulfur in urine. Clin Chem 1980;26:1178-81.

21 Thompson F, Byers T. Dietary assessment resource manual. J Nutr 1994:124:2245-317S

22 Jackson A. Human protein requirements: policy issues. Proc Nutr Soc $2001 ; 60: 7-11$

23 FAO. Body mass index, a measure of chronic energy deficiency in adults (FAO Food and Nutrition Paper, No 56. Rome: Food and Agriculture Organisation, 1994: 1-58.

24 Chiappa K. Principles of evoked potentials. In: Chiappa K, ed. Evoked potentials in clinical medicine. New York: Lippincott-Raven, 1997:1-30.

25 Delisa J, Lee $\mathrm{H}$, Baran $\mathrm{E}$, et al. Manual of nerve conduction velocity and clinical neurophysiology. Philadelphia: Lippincott Williams \& Wilkins, 1994:494.

26 Chiappa K. Pattern-shift visual evoked potentials: methodology. In: Chiappa K, ed. Evoked potentials in clinical medicine. New York: Lippincott-Raven, 1997:31-94.

27 Money GL, Smith AS. Nutritional spinal ataxia. West Afr Med J 1955:117-23.

28 Monekosso GL, Wilson J. Plasma thiocyanate and vitamin B12 in Nigerian patients with degenerative neurological disease. Lancet 1966;i:1062-4.

29 Gidamis A, O'Brien G, Poulter N. Cassava detoxification of traditional Tanzanian cassava foods. Int J Food Sci Technol 1993;28:211-18.

30 Hahn SK. An overview of African traditional cassava processing and utilization. Outlook on Agriculture 1989;18:110-18.

31 Tuboku-Metzger A. Diet and neuropathy. BMJ 1969; iv:239.

32 Oluwole OSA, Onabolu AO, Sowunmi A. Exposure to cyanide following a meal of cassava food. Toxicol Lett 2002;135:19-23.

33 Isom G, Baskin S. Enzymes involved in cyanided metabolism. In: Guengerich F, ed. Comprehensive toxicology, vol 3. New York: Pergamon Press, 1998:477-88.

34 Westley J. Mammalian cyanide detoxification with sulphane sulphur. In: Evered D, Harnett S, eds. Cyanide compounds in biology. New York: John Wlley \& Sons, 1988:201-18. 
35 Davis R, Elzubeir E, Craston J. Nutritional and biochemical factors influencing the biological effects of cyanide. In: Evered D, Harnett S, eds. Cyanide compounds in biology. New York: John Wiley \& Sons, 1988:219-31.

36 Swenne I, Eriksson UJ, Christoffersson R, et al. Cyanide detoxification in rats exposed to acetonitrile and fed a low protein diet. Fundam Appl Toxicol 1996;32:66-71.

37 Tor-Agbidye J, Palmer VS, Lasarev MR, et al. Bioactivation of cyanide to cyanate in sulfur amino acid deficiency: relevance to neurological disease in humans subsisting on cassava. Toxicol Sci 1999:50:228-35.

38 Osuntokun BO, Aladetoyinbo A, Bademosi O. Vitamin B nutrition in the Nigerian tropical ataxic neuropathy. I Neurol Neurosurg Psychiatry 1985;48:154-6.

39 Osuntokun BO, Aladetoyinbo A. Urinary methylmalonic acid in tropical ataxic neuropathy. Lancet 1972; ii:1376-7.

40 Osuntokun BO, Langman MJ, Wilson J, et al. Controlled trial of

hydroxocobalamin and riboflavine in Nigerian ataxic neuropathy I Neurol Neurosurg Psychiatry 1970;33:663-6.
41 Osuntokun BO, Langman MJ, Wilson J, et al. Controlled trial of combinations of hydroxocobalamin-cystine and riboflavine-cystine, in Nigerian ataxic neuropathy. J Neurol Neurosurg Psychiatry 1974;37:102-4.

42 Onabolu AO, Oluwole OSA, Bokanga M. Loss of residual cyanogens in a cassava food during short-term storage. Int J Food Sci Nutr 2002:53:343-9.

43 Foss OP, Lund-Larsen PG. Serum thiocyanate and smoking: interpretation of serum thiocyanate levels observed in a large health study. Scand J Clin Lab Invest 1986;46:245-51.

44 Galanti LM. Specificity of salivary thiocyanate as marker of cigarette smoking is not affected by alimentary sources. Clin Chem 1997:43:184-5.

45 Buzzard M. 24-Hour dietary recall and food record methods. In: Willet W, ed. Nutrition epidemiology. New York: Oxford University Press, 1998:50-73.

46 Money GL. Clinical aspects of tropical ataxic neuropathies related to malnutrition. West Afr Med J 1959:3-17.

47 Cabre P, Smadja D, Cabié A, et al. HTLV-1 and HIV infections of the central nervous system in tropical areas. I Neurol Neurosurg Psychiatry 2000;68:550-7.

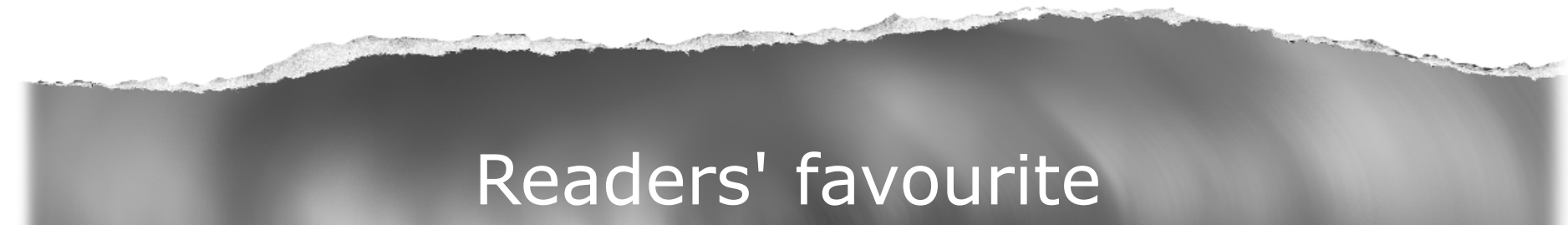

Top 10

Click on the "Top 10" button on the homepage

to see which are the best read articles each month

www.jnnp.com 